University of Wollongong

Research Online

Faculty of Business - Papers (Archive)

Faculty of Business and Law

January 2015

\title{
Mobilizing PD: Professional development for sessional teachers through mobile technologies
}

Bonnie Amelia Dean

University of Wollongong, bcord@uow.edu.au

Michael Zanko

University of Wollongong, mzanko@uow.edu.au

Jan Turbill

University of Wollongong, j-turbill@uow.edu.au

Follow this and additional works at: https://ro.uow.edu.au/buspapers

Research Online is the open access institutional repository for the University of Wollongong. For further information contact the UOW Library: research-pubs@uow.edu.au 


\title{
Mobilizing PD: Professional development for sessional teachers through mobile technologies
}

\author{
Abstract \\ The emergence of mobile technologies has changed the higher education landscape. The expansion of \\ mobile technologies in our classrooms presents new learning opportunities not just for students but also \\ for teachers. While professional development is core business for higher education providers, over the \\ years, increasing attention has been afforded to the growing cohort of casual teachers typically \\ overlooked. Sessional teachers are at the interface of learning, yet have historically experienced limited \\ professional development. A unique opportunity is presented to utilize the flexibly of mobile technologies \\ with the needs of time-poor, provisional sessional teachers. This chapter explores this notion and what \\ this might look like by offering two exemplary cases. These cases demonstrate ways in which to use the \\ affordances of mobile technologies to deliver and customize professional development, thereby \\ embedding professional learning in practice. This is an important strategic, pedagogical, and capacity \\ building movement that currently seems to be lacking in uptake and explication of best practice.
}

\section{Keywords}

mobile, teachers, sessional, technologies, development, mobilizing, professional, pd

\section{Publication Details}

Dean, B., Zanko, M. \& Turbill, J. (2015). Mobilizing PD: Professional development for sessional teachers through mobile technologies. In Y. Zhang (Eds.), Handbook of Mobile Teaching and Learning (pp.

165-182). Heidelberg, Germany: Springer. 


\section{Mobilizing PD: Professional Development for Sessional Teachers Through Mobile Technologies}

Bonnie Dean $^{1} \quad$ Michael Zanko $^{1} \quad$ and Jan Turbill ${ }^{1}$

University of Wollongong, Building 40, 2500 Wollongong, NSW, Australia

\section{Bonnie Dean (Corresponding author)}

Email: bonnie_dean@uow.edu.au

\section{Michael Zanko}

Email: mzanko@uow.edu.au

\section{Jan Turbill}

Email: juturbill@uow.edu.au

\section{Abstract}

The emergence of mobile technologies has changed the higher education landscape. The expansion of mobile technologies in our classrooms presents new learning opportunities not just for students but also for teachers. While professional development is core business for higher education providers, over the years, increasing attention has been afforded to the growing cohort of casual teachers typically overlooked. Sessional teachers are at the interface of learning, yet have historically experienced limited professional development. A unique opportunity is presented to utilize the flexibly of mobile technologies with the needs of time-poor, provisional sessional teachers. This chapter explores this notion and what this might look like by offering two exemplary cases. These cases demonstrate ways in which to use the affordances of mobile technologies to deliver and customize professional development, thereby embedding professional learning in practice. This is an important strategic, pedagogical, and capacity building movement that currently seems to be lacking in uptake and explication of best practice.

Keywords Sessional teachers - Professional development; professional learning - Online teaching Online learning

\section{Introduction}

Australian universities take professional development seriously. Workshops, seminars, guest speakers, career goal setting, and consultations are delivered to build the capacities of the staff. Teachers in particular are offered various opportunities for professional development as teaching is closely linked with quality of education and student learning outcomes.

Over the last several years, greater emphasis has been placed on enhancing the opportunities for teachers who are not permanent, those employed on a sessional basis, to engage in professional development (PD) 
activities. Sessional teachers have been described as the backbone of higher education (Percy et al. 2008 ), yet have historically been overlooked in terms of ongoing support, knowledge building, or practice sharing. They have been excluded as an important community of practitioners through little, or no, induction, training, or ongoing professional development.

The aim of this chapter is to present two professional development programs at the University of Wollongong in Australia that, in different ways, facilitate professional growth through targeting and enhancing teaching practices of sessional teachers. These programs not only address the need for capacity building of sessional staff, but they do so in a way that is compatible with the provisional nature of much casual teaching. Specifically, these programs utilize the affordances of mobile technologies for opening up new ways in which higher education providers can deliver and customize professional development.

This chapter is structured as follows: First is an overview of where professional development is heading: from traditional modes of delivery toward a practice-based focus. Second, literature is presented on research taken to recognize and recommend ways of supporting sessional teachers at Australian universities. Third, new opportunities for engaging teachers through mobile technologies are highlighted through explicating important design principles for mobile learning. Next presented and discussed are two complementary online PD initiatives at the University of Wollongong. Our aim in disseminating these programs is not to evaluate their utility but rather to point to the opportunities created by using mobile technologies for sessional teacher PD through two exemplary cases, one at the institutional level and one addressing a particular faculty and its individual sessional staff needs.

\section{Professional Development in Higher Education}

Professional development of teachers in higher education is important at both strategic and operational levels. In many cases, without some form of institutional support, teachers may fall into the trap of teaching how they were taught or learn "on the job" with little knowledge of alternative approaches or the pedagogical processes that underpin what they do (Johannes et al. 2013).

Professional development initiatives typically include formal, structured learning courses, events, or individual one-on-one consultations convened by either central university teaching and learning units or faculty professionals. These activities are characterized as "push" or "pull" PD delivery models. In a "push" model, learning outcomes are set, and selected information is thrust upon participants to consume within the given timeframe (Shackleton-Jones 2012). In a "pull" model, participants are more selfdirected, choosing to engage in the opportunities that suits them, "pulling" meaningful information forward when needed (Shackleton-Jones 2012).

Concerns have been raised with the nature of some structured courses or "push" models, as well as ad hoc development work, for two main reasons. First, one-off events can preclude ongoing engagement or community building that arises from practice sharing and networking among like-minded peers. Second, formal courses can run the risk of being too far removed from the individual's context (Boud and Brew 
$\underline{2013}$ ). While some professional development support, particularly one-on-one consultations, centers on issues in situ, other courses or workshops take the teacher out of context to discuss different aspects of work. Without this direct link to application, what is learned can potentially fail to make any real change to the teacher's practices.

According to a growing body of practitioners, if PD is to make any lasting impact, it must have direct influence on what a teacher does in everyday learning contexts (Boud and Brew 2013; Debowski 2014; McArdle and Coutts 2010). Boud and Brew ( 2013) suggest the key to effective PD is learning-conducive work that is deliberately located in teaching practices. This model of teacher development moves away from arguments about whether to employ a "push" or "pull" model and instead posits all PD activities take as their core activity practice transformation.

\section{Sessional Teachers: The Precarious Professional}

Sessional teachers are any non-permanent teachers employed on a course-by-course (subject-by-subject) or sessional basis, including postgraduate students, research fellows, industry professionals, clinical tutors, or casually employed lecturers. A substantial portion of university teachers are sessional, with research claiming between 20 and up to $80 \%$ of faculty teachers as sessional or non-permanent (Percy et al. 2008). Sessional teachers are the invisible teachers at the coalface of learning, time-poor postgraduates or individuals that are interested in enhancing the knowledge and skills of learners.

Over the years, research has shown sessional staff experience vastly different opportunities, support, and recognition compared to full-time academic teaching staff. This has extended to poor or lack of induction, training and support, and professional development opportunities (Gottschalk and McEachern 2010; Percy et al. 2008). The degree to which sessional teachers feel supported by the faculty and socially included in the wider teaching community has been found to impact on levels of commitment to teaching (Joiner and Bakalis 2006) and quality of teaching (Myconos 2005). It has also been reported "the quality of education suffers when students are taught by teachers who cannot be available, who are exhausted, demoralized, and frustrated, who lack the time to be as well prepared as they would like to be..."(Dannin 2003, p.10). A number of Australian Learning and Teaching Council (ALTC)- and Office for Learning and Teaching (OLT)-funded projects have focused on investigating these issues. The first of three large-scale studies on sessional teaching explores the recognition, enhancement, and development of casual teachers (also known as RED), by looking at their "significant but largely invisible contribution to the quality of teaching and learning in higher education" (Percy et al. 2008, p. 1). The findings of the RED report substantiate some of the claims in the literature, namely, all universities depend heavily on sessional teachers; sessional teachers are responsible for much of the teaching load; sessional teachers perform a range of teaching-related duties, from casual marker, invigilator, subject designer, and coordinator; and that, universities are unable to report comprehensive and accurate data on the number of sessional staff and their conditions of employment. 
Arising from these concerns, a second project was undertaken to focus on exploring ways academic subject coordinators might lead and manage sessional teaching teams (Lefoe et al. 2011). Entitled the CLASS report (coordinators leading advancement of sessional staff), this project draws together quality processes, practices, and resources as recommendations that might be used across institutions. Their findings and resources are promoted through a website and demonstrated with good practice exemplars (see www.classleadership.com).

The third most recent OLT national study employed a procedure and policy approach by establishing a set of institutional benchmarks from which to evaluate the quality of management and performance issues related to sessional teaching (Harvey et al. 2014). Known as the BLASST report (benchmarking leadership and advancement of standards for sessional teaching), this project established a framework and an accompanying interactive tool (see $\underline{\text { www.blasst.edu.au }}$ ) from which institutions can use to reflect upon and evaluate their own procedures, policies, and practices. This report makes an important distinction between how different departments within an institution can support sessional staff. It distinguishes four levels of sessional support: institutional, faculty/school, department, and individual. At each of these levels, different needs, resources, and responsibilities are required for capacity building and supporting sessional staff (Harvey et al. 2014).

Taken altogether, this literature suggests a number of considerations for the professional development of sessional teachers in higher education. First, while there have been some improvements in the sector, few universities still struggle to adequately integrate and support sessional teachers in both administrative functions and professional development. Second, different approaches are required to address the needs of sessional staff at the different levels within an institution. Third, professional development must be relevant to practice transformation.

Whether the professional development of sessional staff is mandated or made optional and paid or unpaid is a debate for another time. In line with the discussion above, sessional teachers should at least have the opportunity to participate in programs or have access to resources and support that is commensurate with teachers' evolving needs. This means having strategies for professional development in place that are tailored for sessional teachers - but what might these look like and how can they be delivered to a cohort that is so contingent?

\section{In the Palm of Your Hand: New Opportunities to Support Teachers}

As Turbill highlights in Chapter 60, moving from a predominantly face-to-face medium to embracing technological affordances has its own set of challenges. Over the years, a growing body of online courses, resources, or workshops has been developed to build teachers' capacity for this transition to online teaching and learning. These skills include those needed to teach, design, and implement courses through technology, blended with technology or in new-generation learning spaces (de la Harpe et al. 2014). When 
it comes to using mobile technology, a growing body of literature is focusing on ways handheld devices can be used in the classroom, in student-centered teaching and learning activities.

The rapid expansion of mobile technologies in our classrooms presents emerging opportunities to enhance the quality of learning not just for students but also for their teachers. Teachers could benefit from using mobile technologies for professional learning, because as a tool they enable accessible, just-in-time, and flexible delivery of information. This is an important pedagogical movement in higher education academic development that currently seems to be lacking in uptake and explication of best practice.

While professional development through online technologies is useful, it is limited in two ways. First, it targets online teaching skills at the exclusion of other issues, challenges, and insights of being a university teacher. It does not take into account the teacher as a whole person and the contextual sensitivities in which that person teaches. Second, if we are truly interested in skilling our teachers about the enablers of mobile technologies in our classrooms, then why not use this tool for their own learning? When it comes to professional learning and technology, "no amount of practice and coaching will enable someone to use a tennis racket to play golf” (Kim and Reeves 2007, p. 249).

Therefore, using mobile technologies offers an alternative, innovative tool for engaging teachers. Mobile technologies are appropriate for the professional development of teachers because they allow teachers to:

- Remain within the context

- Access and use the device when needed (just-in-time)

- Source what is needed based on own experiences, knowledge, and skill level

- Directly, and readily, transform practice

As Zhang highlights in Chapter 62, there are a number of factors that educators must consider when using mobile technologies, such as the availability of Internet access on campus. Mobile learning is different from online learning, and the users must be placed front of mind in any design. According to Herrington, Herrington, and Mantei ( $\underline{2009}$ ), when incorporating mobile devices into higher education learning contexts, there are several design principles that frame its implementation. These include:

1. Real-world relevance: use mobile learning in authentic contexts

2. Mobile contexts: use mobile learning in contexts where learners are mobile

3. Explore: provide time for exploration of mobile technologies

4. Blended: blend mobile and nonmobile technologies

5. Whenever: use mobile technologies spontaneously

6. Wherever: use mobile technologies in nontraditional learning spaces

7. Whomsoever: use mobile learning both individually and 
collaboratively

8. Affordances: exploit the affordances of mobile technologies

9. Personalize: employ the learners' own mobile devices

10. Mediation: use mobile learning to mediate knowledge construction

11. Produce: use mobile learning to produce and consume knowledge

These principles create an innovative space from which to consider mobilizing PD for sessional staff. The flexibility of using mobile technologies, whenever and wherever, to mediate knowledge construction based on individualized needs fits well for offering professional development opportunities of sessional teaching given the precarious nature of the profession.

\section{Mobilizing PD for Sessional Staff}

Our activities to mobilize PD are drawn from strong pedagogical foundations underpinned and driven by active learning. Active learning is described as "anything that involves students doing things and thinking about the things they are doing" (Bonwell and Eison 1991, p. 2). Rather than watching or listening and passively receiving information, active learning involves two components: experiences and reflection (Fink 2003). By using active learning in PD, our aim is for participants to learn by doing and engage in ways that are relevant for their contexts and purposes.

The initiatives mobilizing PD in the following sections refer to two complementary online programs and resources aimed at supporting and enhancing sessional staff teaching practice. The first is an institutionallevel course for sessional teachers, intended for professional teacher development through structured, optional activities and nurtured through online communities based on sharing, active learning, and reflection. It takes a learning-centered approach to demonstrate and encourage inclusive, active, and collaborative learning environments for quality teaching in higher education (Hunt and Chalmers 2012).

The second is a faculty-based initiative, which produced an online resource designed to be practical and malleable for individual needs. It fits with and extends the first program through offering active learning teaching strategies and contextual, discipline-relevant exemplars. Both initiatives focus on practice transformation front and center. They are also both "pull" models of PD in the sense that they are voluntary and enable accessible, flexible, and "just-in-time" delivery of information and support relevant to sessional teaching.

\subsection{Institutional PD for Sessional Teachers}

The Learning, Teaching, and Curriculum (LTC) unit at the University of Wollongong (UOW) is responsible for a range of programs, services, and supports including coordinating a formal program targeting the continuing professional development of academic staff called the University Learning and Teaching (ULT). ULT is a professional learning program for university teachers designed to enhance 
teaching effectiveness, develop expertise, and provide an educational context for ongoing career development. It engages participants through a series of face-to-face workshops, online modules, and assessments.

LTC introduced Flexi-ULT as an online course for sessional teachers in 2010. It emerged from what had been previously run for several years as a teleconference version delivered to academic staff at its remote campuses situated across the southeast region of New South Wales. Flexi-ULT has transformed the modular design of the workshop series and translated this into an online space to specifically meet the needs of sessional teachers at the University of Wollongong.

Flexi-ULT is a 1-year course conducted online through UOW's learning platform Moodle (see Fig. 1). There are ten modules, each addressing a topic relating to teaching in higher education, for example, "learners and learning," "dealing with challenges in teaching," "active learning," and "teaching online." If a sessional teacher is not able to take a module because, say, they are not teaching for a session or because they have study demands, they can take that module the following year. Once modules 1-9 are complete, participants are eligible for module 10. In module 10, participants deliver either a face-to-face or online teaching session drawing on the strategies and knowledge learned from the course. "Teaching practice" is therefore offered twice a year, in June and November. The ten modules and learning outcomes are shown in Table 1.

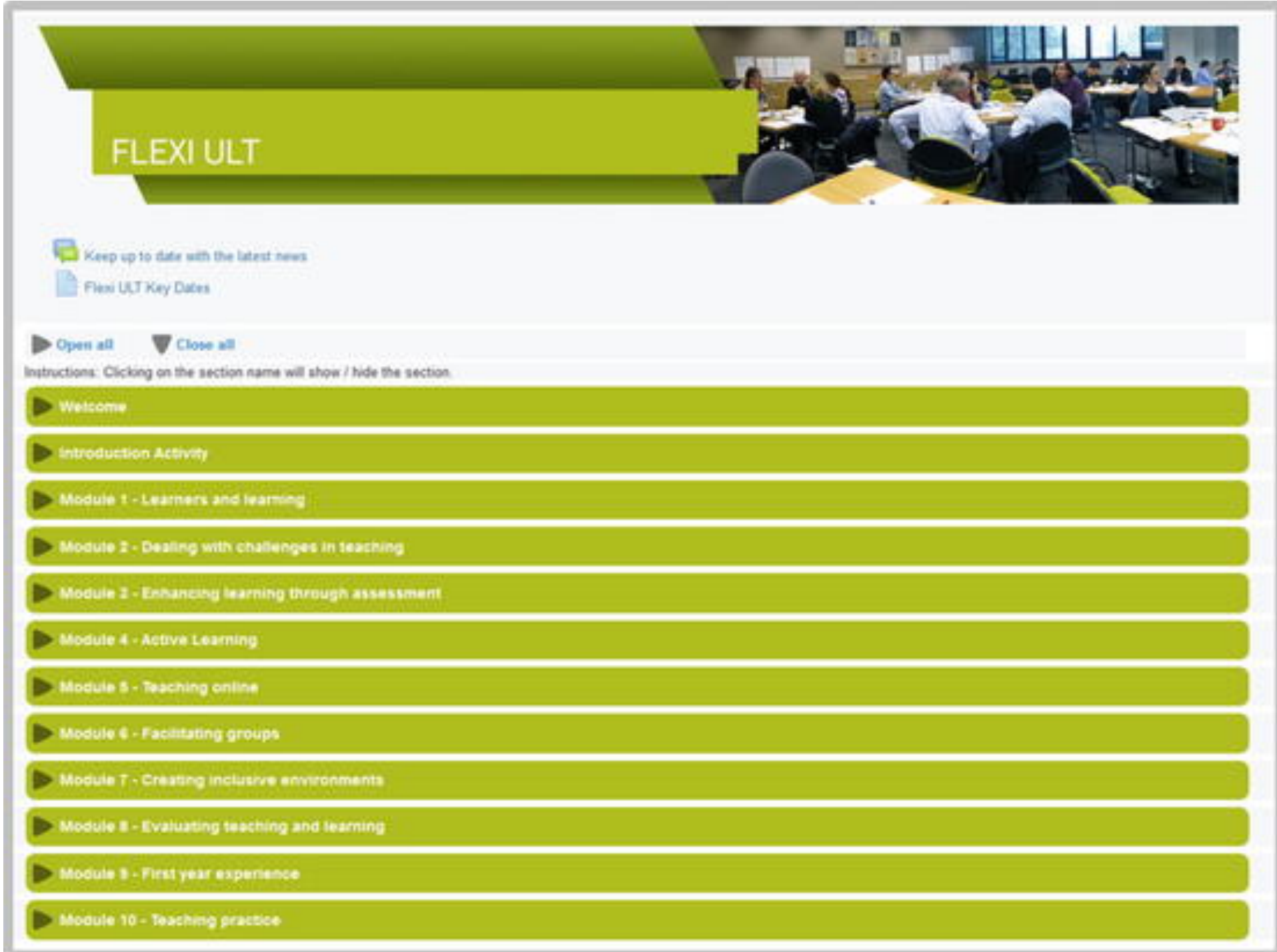

Fig. 1 
Module

1. Learners and learning

\section{Through active participation in this module, you will be able to}

Describe the elements of effective learning in your context

Use your developing theories of learning to plan teaching activities

Explain alternative solutions for dealing with challenging classroom situations

Identify methods to manage the teaching space to create a positive learning environment
2. Dealing with challenges in teaching
3. Enhancing learning and feedback
Practice giving and receiving constructive feedback

Make judgments on marking and provide feedback through an assessment rubric

Share strategies for engaging students in active learning

4. Active learning

Provide feedback on colleagues' teaching activities

Design active learning activities for your teaching context

Discuss the benefits and challenges of teaching online

5. Teaching online

Identify strategies for maintaining an effective teaching presence in online learning environments

Identify strategies for student engagement in online learning environments

Discuss the advantages and pitfalls of group work

6. Facilitating groups
Review and apply UOW policy relating to group work

Develop strategies for managing conflict in groups

Develop a teaching resource to use for group work in your practice

\section{Creating inclusive environments}

Develop an awareness of students' varied circumstances and experiences and how this may impact upon their involvement in higher education Reflect upon your teaching practices

Plan for ways to ensure inclusive practices in your teaching

\section{Evaluating teaching and learning}

Explain the role of formative feedback in evaluating student learning Identify the context of teaching evaluations

Identify a number of formal and informal ways to evaluate your teaching 
9. Teaching students in their

first year
Identify complex factors contributing to a students' first-year experience

Plan teaching activities and strategies to support students in their first year

Plan for and demonstrate knowledge and techniques learned through the course in a teaching session to peers

10. Teaching practice

Reflect on your teaching practice

Evaluate peers' teaching sessions and provide effective feedback

Each module is run asynchronously and is open for 2 weeks. The timing of the modules takes into account the university semester and the teaching and marking peaks for sessional teachers. The modules are activity based to engage learners through active learning - a practice and process that is hoped that sessional staff will adopt in their own teaching. Each module is organized in three activities and is expected to take approximately $3 \mathrm{~h}$. The module design is represented in Fig. $\underline{2}$. There is also one face-toface workshop offered per module to cater for diverse learning styles and preferences. Participants can choose to attend these instead of completing the online activity. Video conferencing for the face-to-face workshop is available to satellite campuses.

\section{Flexi-ULT MODULE DESIGN}

ACTIVITY 1

Introduction

Share thoughts or

experiences
ACTIVITY 2

Engage in activity

around theme
ACTIVITY 3

Action plan

Reflections

Evaluation

\section{Fig. 2}

Flexi-ULT online module design

Activity 1 introduces the theme or topic and provides an opportunity to share thoughts or experiences and activate prior learning. Activity 2 engages participants in the topic through an activity. Examples include compiling a database of teaching strategies, watching a video and responding to a discussion forum, completing a cloze passage (see example set out later in this chapter), selecting subtopics from a list based on own preferences, interviewing fellow teachers and writing a blog, or doing a quiz. Activity 3 summarizes the module through an activity that participants relate directly to their teaching, such as developing an action plan or revising a teaching session. It has a reflective component where participants contemplate what they have read, seen, or done, how this might be implemented, and any remaining questions or concerns. There is also an optional module evaluation. 
Each activity begins with a description of an expected commitment time and a summary of participation to complete the module, e.g., "To complete this activity you are required to post one blog entry and respond to the blog entry of one colleague." Wherever possible, open resources are used, such as YouTube or the College of Fine Arts (COFA) videos and summaries on teaching and learning online (online.cofa.unsw.edu.au/learning-to-teach-online). The activities are not restricted to Moodle capabilities; other free tools are used in the creative design of activities and to expose participants to a range of ideas they may think about using themselves. One tool frequently used are Padlet walls (padlet.com). This tool provides virtual walls that anyone can write on by double-clicking on the wall itself. The result is either a streamline of text boxes or a messy culmination of people's thoughts and experiences strewn across the wall like graffiti.

The flexible, ongoing design of the course establishes and grows a supportive online community of sessional teachers. Sessional teaching can be an isolating experience for many teachers given that there are little opportunities for engagement outside the classroom (Percy et al. 2008). Communities of practice are critical to supporting teachers and are best integrated with reflective learning and opportunities for those reflections to be shared and grounded in practice (McArdle and Coutts 2010). This course is an opportunity for teachers to talk about personal teaching experiences and learn from one another, breaking down isolation by recognizing that others have similar experiences. The Flexi-ULT facilitators focus on developing activities that encourage interaction and reciprocal feedback in a space that is welcoming and safe and creates a sense of belonging (Thomas et al. 2014). For example, the overall course begins with introductory icebreaker activities, and open discussion forums are used for informal conversations within modules and are encouraged outside the space.

Because Flexi-ULT is run at an institutional level, it engages sessional teachers across all faculties. This diversity brings rich, varied perspectives to teaching and practice sharing. The facilitators also make a point of embedding teaching and learning activities within the strategic and contextual frameworks of the institution, for example, by offering web links to UOW contacts for security, learning development or student support advisors, or other policies and guidelines relevant for sessional teaching. However, as Harvey and colleagues ( 2014 ) pointed out in their review of sessional teachers, support can be offered at different levels to cater for different needs. The following section therefore outlines a "just-in-time" approach to support sessional teachers that was developed through a faculty-based project.

\subsection{From Faculty to Individualized PD for Sessional Teachers}

In 2011, a team of academics from the Faculty of Business at UOW received funding from a Higher Education Participation and Partnership Programme grant. This Australian federal government-funded scheme aimed to support domestic students from low socioeconomic backgrounds to enroll and participate in higher education. The project formed part of the approach to support enrolled students, through working with the teachers and the way they designed, scaffolded, and nurtured learningconducive environments. 
subject coordinators of first-year core subjects. A series of workshops and individual consultations were run over the year to assist in the design, delivery, and evaluation of curriculum to engage and support students from low socioeconomic status backgrounds. The success of the first year led to further funding and a snowballing of activities, ideas, and collaborations. As a result, the project ran and was funded for over 3 years. While the first year was directed at working with subject coordinators, the second year took a different focus, investigating how to better support sessional teachers.

First, peer observations of teaching practice were conducted with volunteer sessional tutors. A research assistant, also a sessional teacher, observed six first-year tutorials in core subjects covering management, marketing, finance, accounting, economics, and principles of responsible commerce. Preliminary feedback from these observations highlighted that students were more engaged in tutorials that used activities and group tasks compared to those that required students to simply listen to either the tutor or student presentations. However, it appeared that more technical disciplines (e.g., finance, economics) seemed to move quickly through a set number of problems or practice questions designated for the tutorial, privileging "the covering" of content matter over the learning activity.

Next, to explore the above issues, a focus group was conducted with head sessional tutors with first-year subjects in the Faculty of Business. These core subjects typically have student enrollments in the range of 400-700 students. The focus group involved all ten head tutors of the first-year business core subjects, with one via satellite link. All were paid an auxiliary rate for their time. Tutors were informed that the purpose of the focus group discussion was to identify general issues and concerns that may inhibit teaching and to further use the focus group as a platform to scope interest in professional teaching development.

The focus group confirmed suspicions that had unfolded from the observations regarding the nature of technical disciplines and the constrictions felt particularly from these tutors. In the focus group, they elaborated on their concerns, wanting to know if there was anything they could do in their capacity as tutors given their lack of control over assessments and tutorial outlines. They agreed that they were interested in seeking teaching support and that this was driven by a motivation to better engage students. They also wanted to see examples of how a tutorial activity might work in their discipline.

It became clear there was a need to develop an accessible, "just-in-time" resource specifically for sessional teachers that focused on practical teaching activities and were contextualized within business subjects. With the continued involvement and feedback from the head tutors, an online resource of practical strategies was developed that any teacher could either use spontaneously in the moment to engage students or plan for ahead of time.

The resource was underpinned by Sally Kift's work in the field of transition and first year in higher education. Kift's ( 2009) model offers a framework to support and enhance the first-year student experience (FYE), arguing that a curriculum focus on student diversity was currently the missing link between FYE experience and practice. Her work identifies six interconnected guiding principles of firstyear curriculum: 
1. Transition: consistent and explicit to transition students from prior learning to higher education, through first year and beyond

2. Diversity: attuned to student diversity, accessible and inclusive of all students, and responsive to special needs

3. Design: learner focused, explicit and relevant, and assists student development and engagement in learning environments

4. Engagement: enables active and collaborative learning opportunities

5. Assessment: supportive of a successful transition and increase in complexity from first to later years

6. Evaluation and monitoring: evidence based and regular feedback designed to improve student learning and to intervene in a timely way with students at risk of not succeeding

This accessible online resource focuses on classroom activities, monitored and implemented by teachers facilitating the lesson. It needed to include a suite of sustainable resources that are based on teachers' changing needs - where and when they need it.

To develop the online resources, four experienced and qualified sessional teaching staff were engaged to browse online teaching websites, literature, and materials, to trawl through YouTube, and to talk to other sessional teachers in order to come up with a bank of practical teaching activities. With each activity, exemplars were offered through open learning resources or created using examples from current first-year subjects in the faculty. These examples included digital stories, templates, quizzes, cases, photographs, quotes, and animations. Kift's six principles were used as the organizing framework, as shown in the Fig. $\underline{3}$. 


\section{INCLUSIVE TEACHING IN HIGHER EDUCATION}

\section{More practical strategies}

The following links provide practical activities to cater for diversity in the dassroom. The activities are generic and can be applied to most learning environments. They have been developed as a result of a Faculty of Business Social Inclusion Pricity Scheme (SIPS) project and have been shared here for use by teachers in all faculties.

The activities are organised in the Transition pedagogy framework as identified by the Australian Learning and Teaching Council Senior Fellow Professor, Sally Kaft. More on this work can be found at

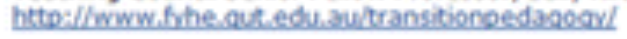

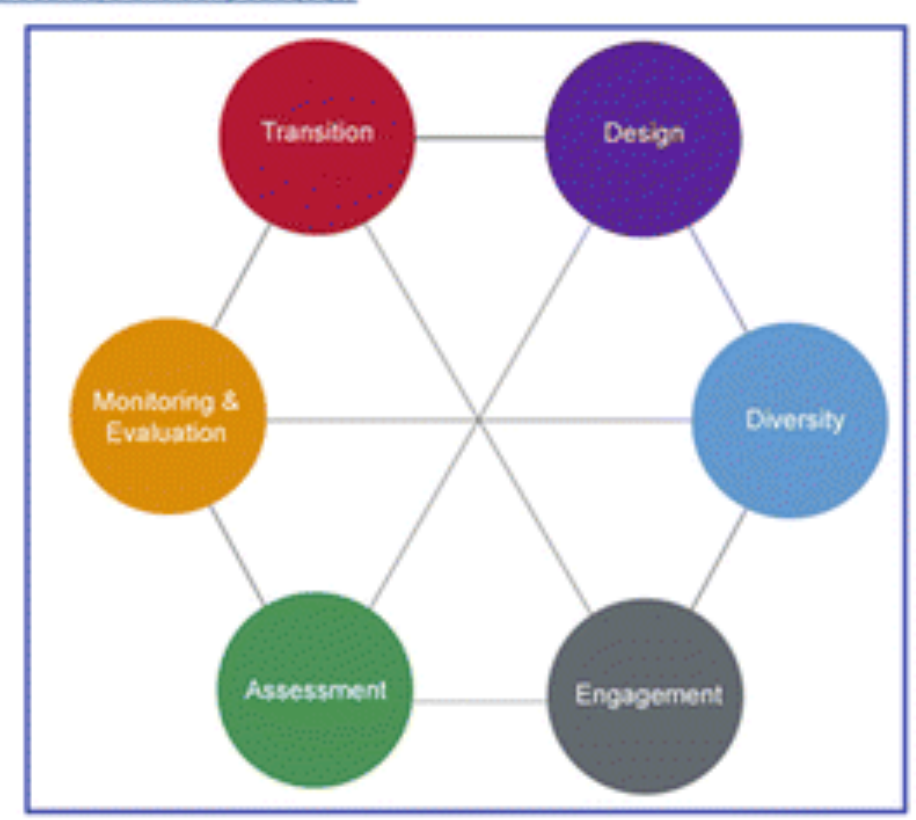

Inclesive teaching in Higher Edecation

BACKGROUND

INFORMATION

- What and Why

FOR TEACMING STAFF

- Introduction

Knowing and respecting your students

- Offering your studenes

Otfering your students
flesobility, variety and choice

Making expectations dear, using

accessible languape

Scatfolding your students'

learning

- Being avalable and

aporoachable to guide student

learning

Being a reflective proctitioner

MORE PRACTICAL

STRATEGIES

Practical strategies from the

Faculty of Commerce

- Trandicion

Diversity

- Design

Engagement

Assessment

Evaluation and Monitoring

References and Resources

CONTACTS

- Contacts Info

\section{Fig. 3}

Screenshot of online resource

It is important to recognize that the activities were not isolated to one principle. To demonstrate the interconnectedness of the principles and how the activities may be used for different purposes, Table $\underline{2}$ was compiled (see below). 
Table 2

Action learning strategies aligned with Kift's principles

\begin{tabular}{|c|c|c|c|c|c|c|c|}
\hline & & Transition & Diversity & Design & Engagement & Assessment & $\begin{array}{l}\text { Eval \& } \\
\text { monitoring }\end{array}$ \\
\hline \multirow{10}{*}{$\begin{array}{l}\text { Transition } \\
\text { Section A }\end{array}$} & First tutorial structure & & & & & & \\
\hline & Unpacking the tutor's role & & & & & & \\
\hline & Student skills self-audit & & & & & & \\
\hline & Helping students set goals & & & & & & \\
\hline & Paraphrase and speculate & & & & & & \\
\hline & Sharing learning criteria & & & & & & \\
\hline & K-W-L charts & & & & & & \\
\hline & Name card tents & & & & & & \\
\hline & Icebreakers & & & & & & \\
\hline & Powerful powerpoint & & & & & & \\
\hline \multirow{4}{*}{$\begin{array}{l}\text { Diversity } \\
\text { Section B }\end{array}$} & Guided instruction & & & & & & \\
\hline & Questioning & & & & & & \\
\hline & Incorrect answering & & & & & & \\
\hline & Communication across language barriers & & & & & & \\
\hline \multirow{10}{*}{$\begin{array}{l}\text { Design } \\
\text { Section C }\end{array}$} & Teaching episodes & & & & & & \\
\hline & Post-it note concept mapping & & & & & & \\
\hline & Reciprocal teaching & & & & & & \\
\hline & Buzz groups & & & & & & \\
\hline & Reading the textbook & & & & & & \\
\hline & Text comprehension & & & & & & \\
\hline & Mapping a text & & & & & & \\
\hline & Helping students understand content & & & & & & \\
\hline & Number heads together & & & & & & \\
\hline & Flipped classroom & & & & & & \\
\hline \multirow{7}{*}{$\begin{array}{l}\text { Engagement } \\
\text { Section D }\end{array}$} & Learning styles & & & & & & \\
\hline & Spatial arrangements & & & & & & \\
\hline & Jigsaw & & & & & & \\
\hline & Pyramid discussion & & & & & & \\
\hline & Question and answer pairs & & & & & & \\
\hline & Think-Pair-Share & & & & & & \\
\hline & Wordle & & & & & & \\
\hline \multirow{6}{*}{$\begin{array}{l}\text { Assessment } \\
\text { Section E }\end{array}$} & Effective assessment & & & & & & \\
\hline & Student self-assessment & & & & & & \\
\hline & Cloze & & & & & & \\
\hline & Traffic lights & & & & & & \\
\hline & Exit tickets & & & & & & \\
\hline & One-minute papers & & & & & & \\
\hline \multirow{4}{*}{$\begin{array}{l}\text { Evaluation } 8 \text { } \\
\text { monitoring } \\
\text { Section F }\end{array}$} & Reflective teaching & & & & & & \\
\hline & Feedback & & & & & & \\
\hline & Student feedback & & & & & & \\
\hline & $\begin{array}{l}\text { Mind-mapping } \\
\text { Effective assessment marking }\end{array}$ & & & & & & \\
\hline
\end{tabular}

\subsection{Examples of Practical Teaching Activities for Sessional Staff}

In what follows are three examples from the online resource. Each is organized under descriptive headings, using easy-to-understand language. Tutors can choose one or several activities to be used in a tutorial, depending of the needs of the students and focus of the tutorial. The activities can be accessed on any mobile device Fig. 4 .

\section{Traffic Lights}

\subsection{What Is It?}

This is a simple strategy for preparing for a test. Tutors provide students with a list of the skills, knowledge, and understandings the test will focus on. Students can evaluate their own readiness by assigning a red, amber, and green light. The resulting record gives students and teachers focus for their revision.

\subsection{How Do I Use It?}


Green light: "I can explain this aspect to someone else."

Amber light: "I think I understand this aspect but I'd have difficulty explaining it to someone else."

Red light: "I don't understand this aspect."

\subsection{Resource}

This video explains how to use traffic lights.

https://www.youtube.com/watch?list=PL4C5A4FEB698EEC1A\&feature=player_embedded\&v=maDJ$\underline{\mathrm{YOHH} 1 \mathrm{~s}}$

\section{Exit Tickets}

\subsection{What Is It?}

Exit ticket is a quick activity at the end of class to summarize and gauge if students have understood the lesson.

\subsection{How Do I Use It?}

Give students "tickets" with space for writing. Ask students two questions: firstly, a factual question about the big idea of the lesson and, secondly, a question requiring more explanation of a concept. Give students $5 \mathrm{~min}$ at the end of class to write their answers. Exit tickets are collected before students leave the tutorial and analyzed to learn how many students understood the big idea.

\section{Cloze}

\subsection{What Is It?}

This is a scaffolded activity for student learning. It is useful for evaluation of comprehension or language or assessing how well students have understood a text of writing.

\subsection{How Do I Use It?}

Construct the cloze by taking a key piece of text and removing about every tenth word. Leaving the first few sentences in place will help establish context. The reader is required to insert a meaningful word in the space (which does not have to exactly match the word in the text if the inserted word maintains meaning - if testing for comprehension).

Take the competed cloze and discuss in groups which words each student inserted and why. A cloze passage may be used to test English comprehension as well as to test subject knowledge.

\subsection{Example: Accounting Discipline}


A business may invest cash in stocks of other corporations. Or a company may buy other types of corporate or government securities. Accounting rules for such can depend on the "intent" of the investment. If these investments were for long-term purposes, or perhaps to establish some form of control over another , the investments are classified as noncurrent

The accounting rules for those types of investments are covered in subsequent chapters. But when the investments are acquired with the simple intent of generating by reselling the investment in the very near future, such investments are classified as assets (following cash on the balance sheet).

These investments are appropriately known as (Adapted from source accessed November 2013 www.principlesofaccounting.com/chapter6/chapter6.html\#Accounting).

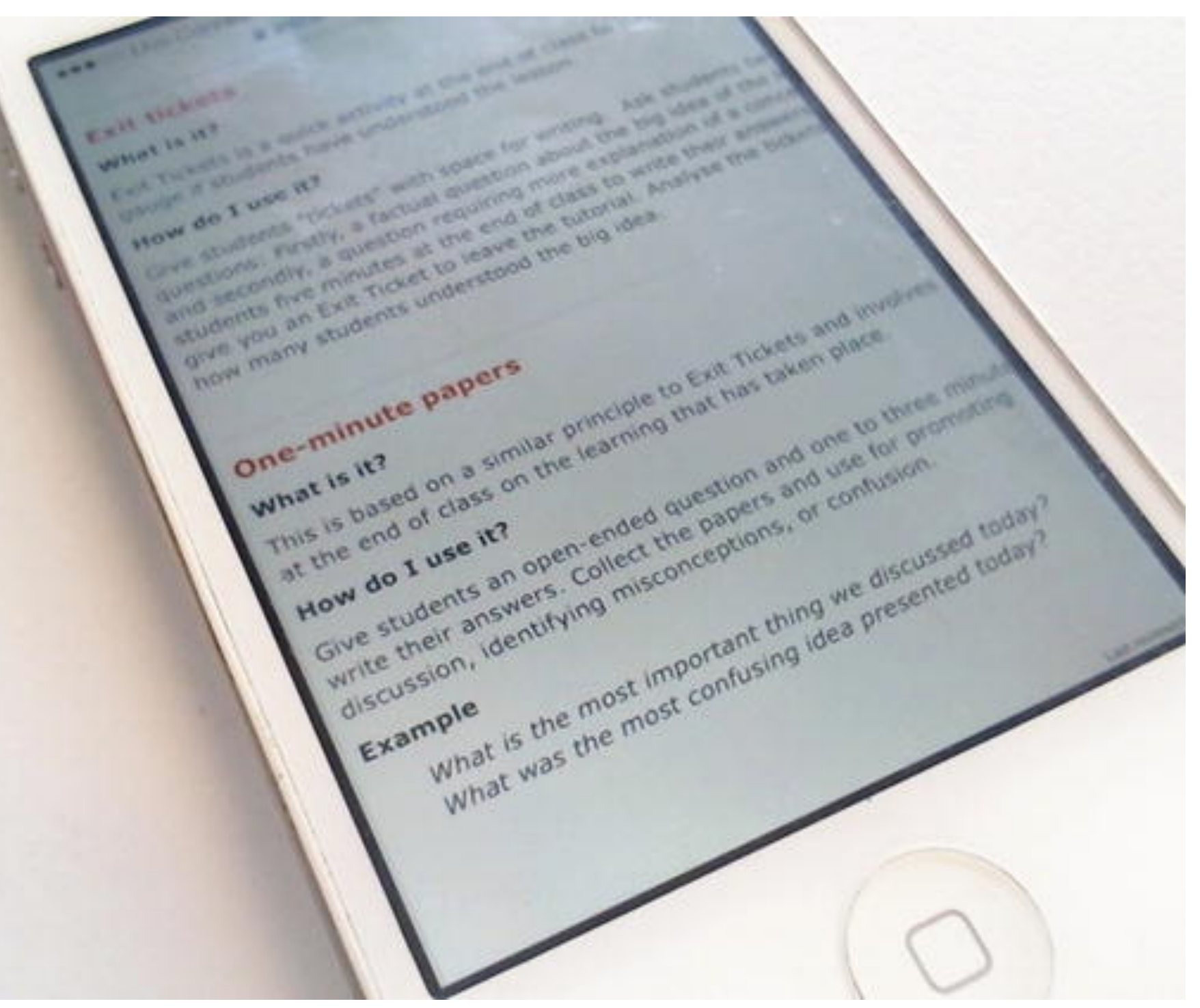

Fig. 4

Accessing the handbook on a mobile device

\section{Future Directions}

This chapter has argued the emergence of mobile devices in our classrooms has opened up new opportunities to engage time-poor sessional staff in professional development. By mobilizing PD, sessional teachers will have greater, flexible opportunities to draw on knowledge, teaching strategies, and ideas and connect with other teachers.

This chapter has suggested PD can and should be mobilized differently at institutional, faculty, and 
individual levels. It has demonstrated this through two exemplary cases at the University of Wollongong.

This approach works toward a figure-ground reversal of the sessional teachers, whereby the contribution of these "invisible teachers" is foregrounded and valued. This is achieved through a direct focus on transforming practice using a tool that allows teachers to remain close to or within teaching spaces and making available practical and proven teaching strategies at the points of planning, preparation, and delivery of a class.

The design, creation, implementation, and sustainability of mobile technologies for professional development in teaching require a significant initial and ongoing institutional commitment. This commitment should ensure that, first, the technologies are current, available, and supported in teaching spaces and, second, that online teaching resources offered are continuously monitored, evaluated, and enhanced. Mobilizing PD is an important strategic, pedagogical, and capacity building movement that requires further research and evaluation yet holds rich potential to enhance the quality of higher education teaching and learning.

\section{References}

Bonwell, C., and Eison, J. 1991. Active learning: Creating excitement in the classroom. ASHE-ERIC Higher Education Report No. 1. Washington, DC: The George Washington University, School of Education and Human Development.

Boud, D., and A. Brew. 2013. Reconceptualising academic work as professional practice: Implications for academic development. International Journal for Academic Development 18(3): 208-221.

\section{$\underline{\text { CrossRef }} \square$}

Dannin, E. 2003. Organizing contingent academics: The legal and practical barriers. Working USA 6(4): $5-11$.

\section{$\underline{\text { CrossRef }[\pi}$}

de la Harpe, B., T. Mason, M. McPherson, E. Koethe, and N. Faulkner. 2014. Not a waste of space Professional development for staff teaching in new generation learning spaces. Final report. Sydney: Office of Learning and Teaching.

Debowski, S. 2014. From agents of change to partners in arms: The emerging academic developer Role. International Journal for Academic Development 19(1): 50-56.

\section{$\underline{\text { CrossRef }[\pi}$}

Fink, D. 2003. Creating significant learning experiences: An integrated approach to designing college courses. San Francisco: Jossey Bass. 
Gottschalk, L., and S. McEachern. 2010. The frustrated career: Casual employment in higher education. Australian Universities Review 52(1): 37-50.

Harvey, M., K. Luzia, C. McCormack, N. Brown, J. McKenzie, and N. Parker. 2014. The Blasst report: Benchmarking leadership and advancement of standards for sessional teaching. Final report. Sydney: Office of Learning and Teaching.

Herrington, A., J. Herrington, and J. Mantei. 2009. Design principles for mobile learning. In New technologies, new pedagogies: Mobile learning in higher education, ed. J. Herrington, A. Herrington, J. Mantei, I. Olney, and B. Ferry, 129-138. Wollongong: University of Wollongong.

Hunt, L., and D. Chalmers. 2012. University teaching in focus. Camberwell: ACER Press.

Johannes, C., J. Fendler, and T. Seidel. 2013. Teachers' perceptions of the learning environment and their knowledge base in a training program for novice university teachers. International Journal for Academic Development 18(2): 152-165.

\section{$\underline{\text { CrossRef }}$ :}

Joiner, T.A., and S. Bakalis. 2006. The antecedents of organizational commitment: The case of Australian casual academics. International Journal of Educational Management 20(6): 439-452.

Kift, S. 2009. Articulating a transition pedagogy to scaffold and to enhance the first year student learning experience in Australian higher education. Final report. Sydney: Australian Learning and Teaching Council.

Kim, B., and T. Reeves. 2007. Reframing research on learning with technology: In search of the meaning of cogitative tools. Instructional Science 35(1): 207-256.

\section{CrossRef $[\pi$}

Lefoe, G., D. Parrish, J. Malfroy, J. McKenzie, and Y. Ryan. 2011. Subject coordinators: Leading professional development for sessional staff. Sydney: Australian Learning and Teaching Council.

McArdle, K., and N. Coutts. 2010. Taking Teachers' Continuous Professional Development (CPD) beyond reflection: Adding shared sense-making and collaborative engagement for professional renewal. Studies in Continuing Education 32(3): 201-215.

\section{CrossRef [}

Myconos, G. 2005. Precarious employment: Reflections from the semi-periphery. Just Policy: A Journal of Australian Social Policy 37(1): 58-62.

Percy, A., M. Scoufs, S. Parry, A. Goody, M. Hicks, I. Macdonald, N. Szorenyi-Reischl, Y. Ryan, S. Wills, and L. Sheridan. 2008. The red report: Recognition, enhancement, development. Australian Learning and Teaching Council. 
Shackleton-Jones, N. 2012. The importance of affective context: Push to pull learning. Global Focus:

Workplace Learning 6(1): 17-20.

Thomas, L., J. Herbert, and M. Teras. 2014 A sense of belonging to enhance participation, success and retention in online programs. The International Journal of the First Year in Higher Education 5(2): 6980.

$\underline{\text { CrossRef }} \square$ 